\title{
Designing User Interfaces in Emotionally-sensitive Applications
}

\author{
Alistair Sutcliffe \\ Manchester Business School, University of Manchester, Booth Street \\ West, Manchester M15 6PB, UK \\ a.g.sutcliffe@manchester.ac.uk

\begin{abstract}
A method for analysing emotion and motivation for design of affective user interfaces is described. Theories from psychology of emotion and motivation are applied in user-centred design to analyse desired influences on users, and plan appropriate UI features, based on a scenario-based approach that analyses affective situations. The method informs design of multimedia and agent-based user interfaces for persuasive technology applications and domains where the user interface may have emotive effects. Use of method is illustrated with a case study in health informatics for a persuasive technology application.
\end{abstract}

Keywords: emotion, motivation, scenarios, interactive agents, persuasive technology, health informatics.

\section{Introduction}

Although emoticons are an established part of the HCI vocabulary, designing user interfaces when emotional reactions are critical is less well understood. The importance of emotion in design of character-based user interfaces has been established by Picard [36], while manipulation of user emotion also plays a central role in games design [7, 26]. ECA (Embodied Conversational Agents) and Human Robot Interaction have used a limited range of emotions, by applying rules linking facial expressions, gaze and body posture [5, 10, 34, 35]. While these areas of HCI provide the means of realising emotion in design they do not advise on how to plan the effect of affect for interactive situations, i.e. how emotional response by users may be anticipated from the affective expressions of agents, and how emotional responses from multimedia content may be anticipated. Design of affective user interfaces has been implicit in games applications, although explicit methods and heuristics to guide designers are not widespread. For example, Callele and colleagues [7] proposed scenario sketches annotated with emotional effects, while Benford and colleagues [4] 
included emotional incidents in their trajectories approach to scripting interaction. However, no systematic taxonomy or heuristics advising on how to apply emotions in design have been proposed. This paper addresses these concerns by proposing a method for analysing affective scenarios and advises on the use of emotional expression in user system interaction. It focuses on identifying the likely emotional state of the user in a given application context, and then user interface design to adapt to the user's emotion.

Emotions are becoming important in a growing class of applications which relate to individual people [30]. Design of persuasive user interfaces may also involve anticipating users' emotional responses to praise and empathetic messages [18]. Further motivation to consider human emotion within the design process arises from the rapid growth of social software; for example, design principles for e-community sites [37] draw attention to social emotions of responsibility and encourage a sense of belonging. Considering emotion a priori enables designers to anticipate human emotional responses and mitigate their downsides, for example by providing sympathetic advice to defuse frustration [27, 33] or adapting content and messages to avoid disappointment.

Many advisory or explanatory systems aim to influence human behaviour; for example, e-health systems may attempt to influence users towards improving their lifestyles. These applications, frequently described as persuasive technology or captology [18], incorporate design features which play on people's emotions. The CASA (Computer As Social Actor) effect [38], which demonstrates that people tend to react to even minimal human presence on computers (i.e. virtual agent, character or even a photograph of a person) as if it were a real person, has been influential in guiding the choice of media, characters, and dialogue content to evoke emotional responses. Although some methods for using affect in persuasive applications have been developed [19], no general approach for affect-based UI design has been proposed.

A systematic approach is therefore needed to address how people may react to potentially affect-laden situations and to plan productive design influences on human emotion while avoiding adverse responses. This paper proposes a model and process for analysing the role of emotion in interactive, user-centred applications, with design advice directed towards agent-based interfaces and social software. In the next section, previous literature in HCI and related disciplines is reviewed. In section 3, models and theories of motivation and emotion are briefly reviewed, with their relevance to UI design. A process of analysing emotional responses by stakeholders and specifying requirements for affective applications in described in section 4, followed by an illustration of the process in a persuasive e-health application case study. The paper concludes with a discussion of the prospects for affective UI design.

\section{Related Research}

Emotional response to user frustration by providing sympathetic messages has been demonstrated to improve performance and user attitudes [27, 33], while affective design has been widely applied in ECAs $[35,36]$ and robotics, where use of emotions 
portrayed by non-verbal communication has been shown to persuade users more effectively [10]. Emotion and motivation are key features of emotional design methods; for instance, manipulation of hope/fear or social acceptance/rejection [19], and guidelines in many persuasive design methods are based on manipulating users' affect either via CASA principles [38], or by rhetorical argument applied to dialogue design [39]. Design guidelines for achieving affect in character-based interfaces can be based on taxonomies of facial expressions and voice prosody effects as well as use of colour and selection of media for mood manipulation [6]; however, analysing users' responses and design of affective user interfaces has received less attention.

A method for designing for affect in games applications has been proposed by Callele [7], as a process of scripting with storyboards and scenarios for planning user interaction. Design effects to evoke emotions such as surprise and fear were annotated on to drawings of the game world; however, no particular model of emotion was proposed. Value-based design [21] elicits user feelings and attitudes to potential systems by presenting cue cards associated with possible emotional responses and user values. Scenarios and storyboarding techniques are used to elicit stakeholder responses, but value-based design does not focus directly on user emotions; instead, it aims to elicit users' attitudes and feelings about products and prototypes as an aid towards refining requirements with human-centred values. Values and affective responses have been investigated by Cockton et al. [11] in worth maps, which attempt to document stakeholders' views about products or prototypes. Worth maps may include emotional responses, but their main focus, similar to value-based design, is to elicit informal descriptions of potential products expressed in stakeholders' language of feelings, values and attitudes. User Experience (UX) has described affective aspects of products [25], drawing attention to aesthetics and enjoyable properties of interactive applications, but no guidelines have been proposed about how to analyse UX or for designing features to deliver an enjoyable user experience.

The role of emotion in user-centred design of products was highlighted by Norman [31], who argued that good design should inspire positive emotional responses from users, such as joy, surprise and pleasure; however, Norman was less forthcoming on how to realise affect-inducing design, beyond reference to the concept of affordances, intuitively understandable user interface features. Techniques for exploring affect in requirements include use of personas, pen portraits of typical users, with their feelings and possibly emotion in their personalities [12]. Personas were developed further into extreme characters [15] as a means of eliciting stakeholders' feelings to provocative statements about designs, although neither of these techniques considered the role of emotion explicitly. Requirements for emotion are tacitly included in design of embodied conversational agents [5,9] as scripts for controlling facial expression, posture and gaze of virtual agents; however, the ECA literature contains few techniques for eliciting or specifying desired emotional responses.

\section{Theories of Emotion and Motivation}

As Brave and Nass [6] point out, affect-oriented design concerns users' needs as well as their emotions. Two areas of psychology are relevant to personal needs: first, motivation theory, which explains deep-seated goals or drives which determine our 
behaviour; and secondly, emotions, which characterise our automatic reactions to events and situations. The intention is to augment user-centred design (UCD) with knowledge from psychology about users' goals which are tacit (motivation), and reactions that may arise when goals or motivations are frustrated (emotions). Psychologists distinguish between emotions, which are specific responses, and moods, which reflect more general good or bad feelings. Moods are general states, whereas emotions are part of our cognitive response and persist as memories of responses to events, objects and people. Emotions may be either positive (pleasure and joy) or negative (fear, disgust) and may have a force, e.g. worry or anxiety is a mild form of fear. There are many theories of emotion; however, three have received more attention in the design of software systems. First, Norman's model [31] divides emotional responses into three layers: the visceral layer which produces psychosomatic responses to fear and anger; a behavioural layer that dictates actions in response to emotion, such as rejecting a product; and finally a reflective layer in which emotional responses are rationalised, e.g. disappointment in a product after a poor user experience. Norman advises that software design should encourage emotions of pleasure, joy and surprise for positive behavioural and reflective responses, but gives little advice on how to achieve such responses in a design. Second, ECA designers have favoured Ekman's theory [16] which characterises a simple set of basic emotions: anger, disgust, fear, sadness and surprise, which are communicated by facial expressions. The third more comprehensive theory is the OCC (Ortny, Clore, Collins) model [32] which contains a taxonomy of 22 emotions, classified into reactions to events, agents (other people) and objects, and which may be either positive or negative. A simplified view of the OCC taxonomy is shown in Fig. 1. Reaction to events depends on whether the consequences concern oneself (+ve hope, -ve fear) or others, and then the impact of the event (satisfaction, fears confirmed/relief, disappointment). Responses to objects may either be mild (like or dislike) or stronger (love/hate). Emotional response to agents' actions depends on who the action relates to (self, others, group) and then the perceived effect of the action and whether it was positive, such as pride as a positive response to one's own action, or reproach as a negative reaction to another person's action. Event-related emotions are responses to situations and changes in the environment and related either to oneself or others in terms of consequences and impact. For example, joy is a positive assessment of an event (e.g. birthday party) relating to oneself with a general impact, and hope is the positive emotion in a specific response to getting a present, which may than happen (satisfaction) or not (disappointment). Some emotions, such as gratification, remorse, gratitude and anger, are complex responses to events and agents/objects. Even though the OCC model is comprehensive it does not account for social emotions such as empathy (+ve reaction to an agent) and belonging ( + ve reaction to group membership) [3]. In spite of these limitations the OCC model is suitable for application to requirements analysis since the event/agent/object taxonomy and decision tree can be applied to analysing emotional reactions. Individual stakeholders may experience emotions in response to events, objects or agents produced by the software system, or which may be a consequence of events and objects in the system environment. Once a range of "emotion inducing" states has been identified, responses to them can be planned for software agents and multimedia systems. 


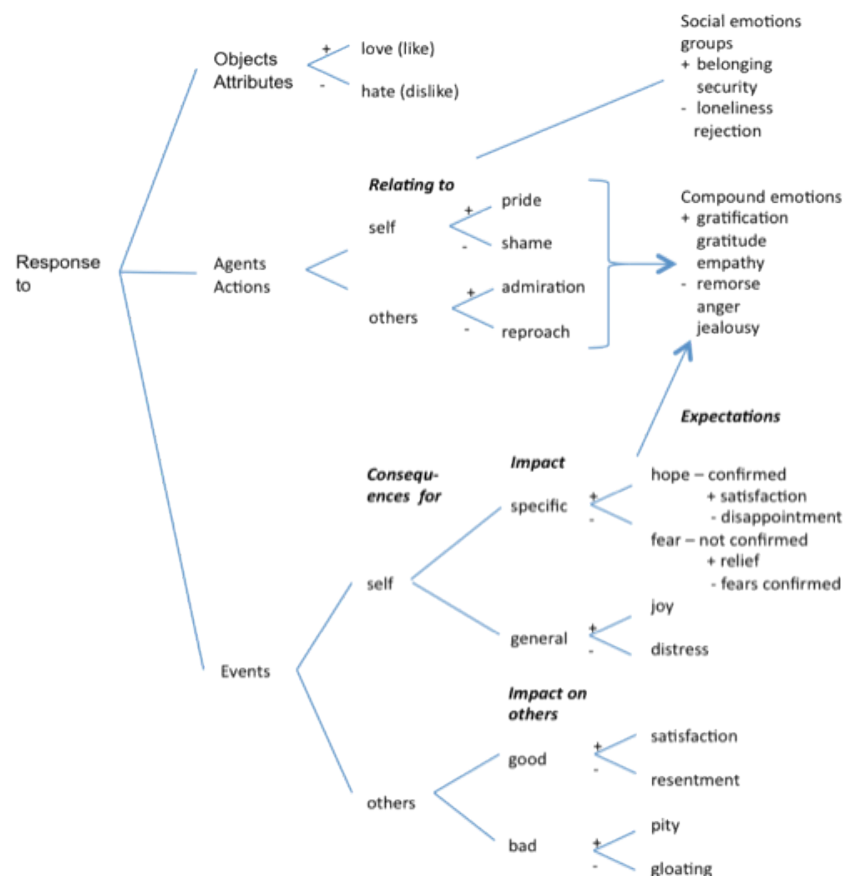

Fig. 1. OCC model decision tree for classifying emotions; augmented with social emotions

\subsection{Motivation Analysis}

Motivations were classified by Maslow [28] into levels ranging from basic bodily needs such as hunger and thirst, to higher-level needs for security, comfort and safety, and finally socially related motivations of self-esteem and altruism. Table 1 summarises the more important motivations for requirements analysis, synthesised from Maslow's motivation theory. Column 2 describes the motivation as hints for analysis questions, some of which are suggested by the motivation type itself, i.e. questions about interest in learning, or willingness to help others. Column 3 suggests high-level UI or socio-technical design implications for each motivation type; for example, self-efficacy, curiosity and learning point towards the need for opportunities to experiment which may suggest end-user development facilities.

Safety subsumes basic physiological motivations to satisfy hunger, thirst, and protect oneself. Power, possession and achievement are all related directly to personal goals, although in different ways. Power is manifest in actions and social relationships, and is associated with responsibility, trust, and authority. Possession is more personal, concerning goals to own resources, wealth or products. Achievement (or failure) is the end state of most goals, although in motivation theory it spans many personal goals as a lifetime ambition. Self- and peer-esteem concern personal perceptions of self and of self by others, which may indirectly be related to goals if achievement is frustrated, leading to a decline in self-esteem. Motivations of 
achievement, self- and peer-esteem are important in persuasive technology design to suit individual needs; for instance, in e-commerce, marketing tools can be customised to praise customers $[18,19]$ and thereby improve their self-esteem (positive well being).

Table 1. Motivations and their consequences

\begin{tabular}{|c|c|c|}
\hline Motivation & Description & Design Implications \\
\hline Safety & $\begin{array}{l}\text { Self preservation, avoid } \\
\text { injury, discomfort }\end{array}$ & $\begin{array}{l}\text { Avoid danger: safety critical applications; } \\
\text { avoid natural and artificial threats to self }\end{array}$ \\
\hline Power & $\begin{array}{l}\text { Need to control others, } \\
\text { authority, command }\end{array}$ & $\begin{array}{l}\text { Work organisation, responsibility, control } \\
\text { hierarchy }\end{array}$ \\
\hline Possession & $\begin{array}{l}\text { Desire for material goods, } \\
\text { wealth }\end{array}$ & $\begin{array}{l}\text { Resource control, monetary incentives, } \\
\text { ownership, products, wealth }\end{array}$ \\
\hline Achievement & $\begin{array}{l}\text { Need to design, construct, } \\
\text { organise }\end{array}$ & $\begin{array}{l}\text { Project \& personal goals, completing tasks, } \\
\text { lifestyle targets }\end{array}$ \\
\hline Self-esteem & $\begin{array}{l}\text { Need to feel satisfied with } \\
\text { oneself }\end{array}$ & $\begin{array}{l}\text { Linked personal goals, personal achievement, } \\
\text { also perception of self }\end{array}$ \\
\hline Peer-esteem & $\begin{array}{l}\text { Need to feel valued by } \\
\text { others }\end{array}$ & $\begin{array}{l}\text { Inclusion in groups, teams social feedback } \\
\text { and rewards, praise }\end{array}$ \\
\hline Self-efficacy & $\begin{array}{l}\text { Confidence in own } \\
\text { capabilities }\end{array}$ & $\begin{array}{l}\text { Confidence building, training, encourage } \\
\text { responsibility }\end{array}$ \\
\hline $\begin{array}{l}\text { Curiosity, } \\
\text { learning }\end{array}$ & $\begin{array}{l}\text { Desire to discover, } \\
\text { understand world }\end{array}$ & $\begin{array}{l}\text { Opportunities to experiment, time to explore, } \\
\text { self tutoring and learning support }\end{array}$ \\
\hline Sociability & Desire to be part of a group & $\begin{array}{l}\text { Group membership and social relationships, } \\
\text { collaboration in work }\end{array}$ \\
\hline Altruism & Desire to help others & $\begin{array}{l}\text { Opportunities and rewards for helping, } \\
\text { selfless act }\end{array}$ \\
\hline
\end{tabular}

Self-efficacy is realising one's potential, hence increasing abilities and responsibility. Altruism and sociability are social motivations driving group behaviour, the need to belong to groups and undertake selfless acts, which incidentally increases peer esteem and hence the sense of belonging to the group. People with high sociability motivation will collaborate and cooperate with others in group working. Motivations can be measured by questionnaires; however, simple checklists of motivations are sufficient to direct analysis in most applications.

\section{Applying Emotions and Motivations in UCD}

The taxonomies of emotions and motivations are used as tools for thought in scenariobased design (SBD) [8]. Motivational analysis extends analysis of users' needs in personae and SBD; in contrast, emotions are reactions, and consequently these fit as a means of assessing the implications of situations. The affective UCD process is summarised in Fig. 2. 


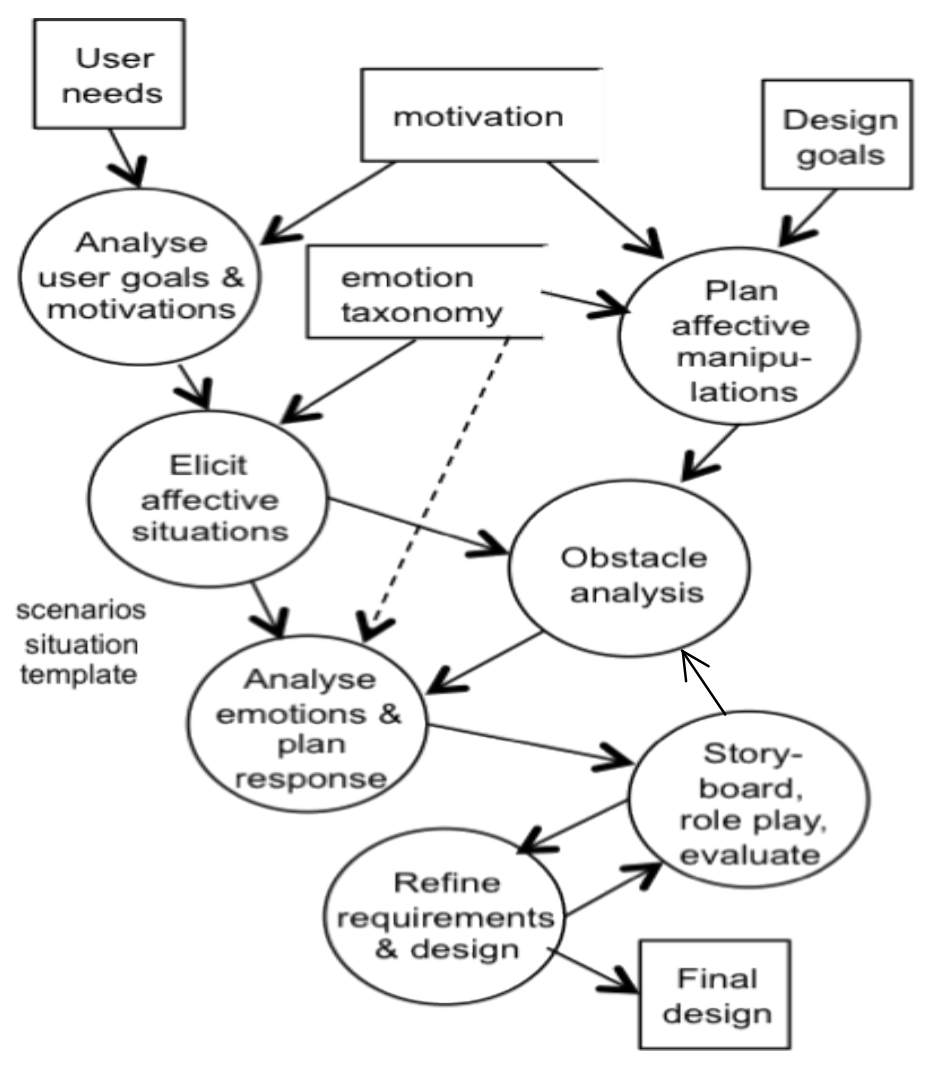

Fig. 2. Summary of the Emotional UCD process

The process follows two related pathways: first, the analysis path that starts from users' needs where the motivation component in the EUCD method is applied; then, affective situations are considered by identifying scenarios for the user roles and stakeholders who may experience significant emotions, followed by analysis of the situations and events that may lead to emotional experiences. Barriers to achieving personal goals and motivations are investigated in "what if" scenario analysis, as well as problems in achieving the desired emotional reaction. The second planning path has its origins in design goals to influence users and their personal goals. System agents and actions are specified in response to anticipated situations. The two pathways interact: the system goals planning pathway suggests situations for followup analysis, while affective situations identified in the domain may alter plans and system goals. Analysis of affect may be stimulated by the type of application; for example, games and entertainment applications aim to manipulate user emotions, while e-commerce applications have design goals to influence decisions of individual stakeholders and user groups.

Design goals may arise from the need to motivate users to change their behaviour or persuade them towards certain decisions in applications such as healthcare 
(lifestyle behaviour), marketing e-commerce (purchasing decisions) or social ecommunities (persuade people to participate).

\subsection{Analysing User Goals and Motivations}

Analysis of users' goals follows conventional interviews and scenario-based techniques augmented with motivation analysis using the taxonomy. For example, personal goals to improve one's diet and take exercise will be related not only to achievement but also to self-esteem (feeling good about oneself) and peer esteem (improved standing among friends having lost weight). Barriers to personal goals may have motivational implications such as frustrated achievement, power and possession, which in turn may have knock-on effects on self-esteem and peer-esteem. Since emotional responses are frequently related to motivations as well as to our short-term goals and aspirations, analysis of motivations, goals and emotions is inevitably intertwined. A summary of motivations and possible barriers to their realisation, and emotional responses to frustrated motivation, is given in Table 2.

Table 2. Motivations, obstacles and responses

\begin{tabular}{|c|c|c|}
\hline Motivation & Barriers/Threats & Possible emotional response and (mitigation) \\
\hline Safety & $\begin{array}{l}\text { Dangerous events, } \\
\text { malevolent agents }\end{array}$ & $\begin{array}{l}\text { Fear, hate (remove cause or relocate user, add } \\
\text { defences and counter measures to events }\end{array}$ \\
\hline Power & $\begin{array}{l}\text { Change to authority, } \\
\text { responsibility }\end{array}$ & $\begin{array}{l}\text { Anger, shame, resentment (compensation, } \\
\text { change people, relationships) }\end{array}$ \\
\hline Possession & $\begin{array}{l}\text { Reduced resource control, } \\
\text { monetary incentives }\end{array}$ & $\begin{array}{l}\text { Anger, jealousy, resentment (reallocate } \\
\text { resources, responsibilities, change people) }\end{array}$ \\
\hline Achievement & $\begin{array}{l}\text { Constraints on goals, } \\
\text { actions }\end{array}$ & $\begin{array}{l}\text { Anxiety, frustration resentment (change goals, } \\
\text { remove constraints) }\end{array}$ \\
\hline Self-esteem & $\begin{array}{l}\text { Adverse events, goals not } \\
\text { achieved }\end{array}$ & $\begin{array}{l}\text { Shame, anger (re-focus goals, emphasise other } \\
\text { achievements) }\end{array}$ \\
\hline Peer-esteem & $\begin{array}{l}\text { Adverse interactions, } \\
\text { events }\end{array}$ & $\begin{array}{l}\text { Rejection, loneliness (focus on }+ \text { ve social } \\
\text { relationships) }\end{array}$ \\
\hline Self-efficacy & $\begin{array}{l}\text { Limitations on actions and } \\
\text { responsibilities }\end{array}$ & $\begin{array}{l}\text { Disappointment, distress (improve opportunities, } \\
\text { challenges) }\end{array}$ \\
\hline $\begin{array}{l}\text { Curiosity, } \\
\text { learning }\end{array}$ & $\begin{array}{l}\text { Excessive workload, time, } \\
\text { resources }\end{array}$ & $\begin{array}{l}\text { Disappointment, reproach (provide time, change } \\
\text { workload) }\end{array}$ \\
\hline Sociability & $\begin{array}{l}\text { Group conflict, } \\
\text { personality and authority } \\
\text { clashes }\end{array}$ & $\begin{array}{l}\text { Rejection, resentment, loneliness (negotiate } \\
\text { problems, change group membership, } \\
\text { responsibilities }\end{array}$ \\
\hline Altruism & Limitations on actions & $\begin{array}{l}\text { Distress, disappointment (provide opportunities, } \\
\text { rewards) }\end{array}$ \\
\hline
\end{tabular}

The motivations and emotions listed in Table 2 can be used to prompt questions in both directions. Emotional reactions to a scenario may indicate motivational problems, while barriers to personal goals and related motivations indicate emotional 
consequences which will need to be addressed either in the social system or design of information content and artificial agents.

\subsection{Identifying Affective Situations}

The first step is to identify the range of potential affective situations, then to trace the source responsible for emotional reactions in the system content or environment. Situation analysis is directed towards identifying the possible emotional response and its source, then establishing requirements for system agents and responses using the template illustrated in Table 3.

Table 3. Affective situation requirements template, with notes

\begin{tabular}{ll}
\hline Application & Situation ID \\
\hline Agents \& actions & $\begin{array}{l}\text { People in the scenario, possible actions and communication } \\
\text { Objects }\end{array}$ \\
$\begin{array}{l}\text { Events (previous) } \\
\text { Expected events in the environment, with their source, when } \\
\text { known. User memory of previous events }\end{array}$ \\
$\begin{array}{l}\text { Expected emotion } \\
\text { As identified from the above and obstacle analysis } \\
\text { Agent requirements }\end{array}$ & $\begin{array}{l}\text { Remove cause, mitigate effect } \\
\text { Other requirements }\end{array}$ \\
\hline
\end{tabular}

Scenarios, use cases and storyboards, all commonly practised UCD techniques, can be adapted for "affective situation" analysis with stakeholder groups and individual users. Scenarios describing potential emotion-invoking incidents may be elicited from stakeholders or created by analysts to explore user reactions to personal goals and design features. Storyboards and sketches are used to illustrate scenarios and are presented to users to capture their responses. Since agent-based technology is now cheap and easy to use, lightweight prototypes can be developed to explore design options with a range of emotional expressions by agents [2]. Some examples of facial expression of emotions using agent prototyping tools are illustrated in Fig. 3.

Facial expression alone is somewhat ambiguous, as might be discerned from Fig. 3 , so it needs to be combined with dialogue, for example "you seem to have difficulty in placing this order, please select the product again" and "thank you for you order, please proceed to payment" in a typical e-commerce sequence. Emotional expression is even more effective when prosody (voice tone) is used, and text to speech output with limited tonal expression is provided by agent development tools. 


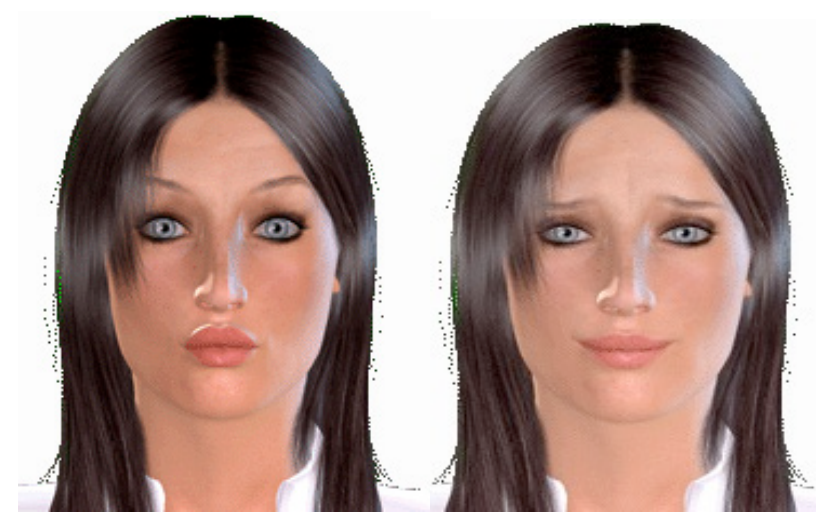

Fig. 3. Expression of emotion by agent's face with dialogue excerpts. Left: "You seem to have problems; can I help you?"; Right: “... all is ok; please continue”.

\subsection{Analysing Situations and Emotions}

Tracing the source of emotions follows the template and OCC decision tree to elicit the reasons for the response, then identifying the source in the system environment, content or the design itself. The OCC decision tree helps to identify potential emotions and their causes by asking questions about the source of the problem (agents' actions, objects' attributes, events), who it affects (self, other stakeholders), and the consequences and impact of the problem as well as any previous related experiences (expectations). Affective reactions may be caused either by the system design, the content of the design, agents, especially people and other stakeholders, actions, or events in the system environment the user has to deal with. Poor implementation of requirements or missing requirements may evoke frustration and anger in more extreme cases. User reaction to the content of applications and websites may be more complex as the response may be caused by information and messages conveyed by text or speech, images of people or natural phenomena, or even sounds and music. Situations involving the system environment range from other people in computer-mediated communication and social software, to events in the world or user goals that the system has to respond to by advising, persuading or directing the user to take action.

Anger tends to be associated more closely with agents and people, so the presentation of characters, opinion and values that clash with the stakeholder's viewpoint should be investigated. Fear is related to events as well as to specific agents, so events in the system environment or described in the system content (e.g. website information) should be questioned. Disgust is a strong, visceral emotion usually associated with content, for example images of putrefying food. Socially oriented emotions have roots in reactions to people and events, so in this case the stakeholder's relationship with others may need to be investigated, through the history of events involving the user and others in the system environment. Social emotions are also important considerations in social computing applications, with privacy and security implications. For example, disclosure of secrets may cause shame (in own 
behaviour), jealousy (in others) remorse (in injudicious actions which have offended others) and so on. Scenarios of information disclosure and privacy controls can explore the types and strengths of emotional responses.

\subsection{Scenario-barrier Analysis}

Planning system responses to user emotions can be helped by analysing obstacles to motivations and personal goals. If responses can invoke appropriate user motivations then potential negative emotions might be deflected or converted into positive responses (e.g. convert dislike into like by changing an object or design). Since motivations are long-term goals, barriers will tend to be more general and persistent than may be expected for short-term personal goals. Table 4 gives some guidance in analysing possible reasons for affective reactions for a sub-set of OCC negative emotions.

Table 4. Emotions, possible causes and responses

\begin{tabular}{|c|c|c|}
\hline Emotion & Barriers, causes & Possible responses/mitigations \\
\hline Hate & $\begin{array}{l}\text { Actions of people or things, } \\
\text { value clashes }\end{array}$ & $\begin{array}{l}\text { Remove object, agent; change focus to self- } \\
\text { achievement }\end{array}$ \\
\hline Anger & $\begin{array}{l}\text { Offensive events, people, } \\
\text { things, values }\end{array}$ & Remove cause, mitigate reasons \\
\hline Fear & $\begin{array}{l}\text { Threats to self, dangerous } \\
\text { objects, situations }\end{array}$ & $\begin{array}{l}\text { Remove threat or user from situation, add } \\
\text { protection }\end{array}$ \\
\hline Disgust & Offensive objects, people & Remove cause, change location \\
\hline Jealousy & People's actions, objects & Mitigate reasons, change focus to self \\
\hline Shame & Own actions self-image & Analyse reasons, change focus to achievement \\
\hline
\end{tabular}

The causes (agents, people, events, etc.) may hinder the achievement of personal goals while column 3 gives limited guidance on countermeasures. Motivational consequences may be mitigated by design in the social system, for example, poor selfesteem arising from a lack of achievement may be alleviated by improving training, changing the organisation of work, or re-setting targets to make them more achievable. Emotional responses indicated from the motivation barrier analysis suggest further scenarios where the implications can be explored by role-playing situations in which the generic obstacles are made more realistic and concrete, e.g. being turned down for promotion frustrates achievement and has a negative impact on self-esteem.

\subsection{Planning Responses}

The source of the emotional response is traced back to the agent, action or event, and response scenarios are planned to mitigate the anticipated negative emotion. Once the source is known, responses to deal with the situation can be specified. There are three main routes: first to remove the source; secondly to reassure the users and diffuse the 
emotion by reducing the significance or impact of the reaction; and finally planning a system response to change negative affect into its related positive emotion, e.g. fear is converted into relief by explaining that the event's consequences are not what the user expected. Removing the source in content can be achieved by editing to remove the offending image, text or event; however, changing sources in the system environment may not be an option, so a mitigation strategy may be necessary. For example, if resentment is felt in response to the success of others, then a better outcome might be to convert this into satisfaction or deflect the negative emotion by urging the user to reflect on their own achievements. Resentment might be reduced by counselling the user to ignore the event as unimportant or reflecting on their own success rather than envying others.

Hate and its milder manifestation (dislike) may be encountered as a response to missing requirements, poor user interface design, or when users are frustrated by poor design. With content, the causes may arise from a clash between the user's beliefs and values and information or opinions expressed in the content. Adverse reaction to personalities is another likely cause. Emotional responses to products and designed artefacts are usually easier to deal with since these can be traced back to the feature causing dislike. Disliked features indicate poor design or missing/inappropriate requirements.

Positive emotions are less of a concern in situation analysis since there are fewer implications for system requirements, although when goals for influencing user behaviour are present, then scenarios need to be developed that describe the desired positive emotion, e.g. pleasurable experience for persuading users. To illustrate, in an e-commerce application selling high-quality design goods such as jewellery, the system goal is to influence the user to buy the product. The user is a member of the public, objects are the jewellery products, and the intended emotions are curiosity, pleasure and desire. Requirements for a sales agent's virtual character are to empathise with the user, using a smiling facial expression to communicate interest and pleasure in explaining the product, followed by actions to demonstrate product qualities, and use of gesture and gaze to draw attention to these features. In games applications a sequence of affective situations will lead the user-player through interactive episodes with agents and events to evoke fear, anxiety, surprise and relief as the game sequence unfolds. Action scripts and sketches of the game's virtual world amplify the requirements described in the template.

\section{Case Study Application of EUCD}

In this section, use of the Emotional UCD process in a persuasive technology application in e-health is described.

\subsection{Detecting Early Onset of Cognitive Impairment}

The system is intended to help early diagnosis of cognitive dementia and Alzheimer's disease among the elderly. Unfortunately, Alzheimer's disease is diagnosed too late in too many people, by which time there is little that medical science can do to help; however, if the disease is detected early, then treatments can delay its onset and 
ameliorate its symptoms. Early onset can be detected by memory tests, patterns of word use and motor reaction times, so the high-level system goal is to remotely and unobtrusively monitor people's use of home computers and text-based messaging via e-mail and social networking sites. There are many complex requirements involving data and text mining to produce early onset diagnostic indicators, which do not concern this paper; instead, analysis of the users' possible reactions to the system are described, with the aim of persuading elderly users to self-refer for follow-up tests and appropriate medical treatment.

The users' motivation is safety, to avoid Alzheimer's disease if possible; with personal goals to participate as volunteers in the trial for altruistic reasons. Affective situations in this case are an obvious consequence of the design goal to warn the user. The affective UCD problem is to analyse people's potential reaction to system diagnoses. The diagnostic part of the system will not be perfect, hence there is uncertainty about the results and the danger of false positive diagnoses, which could provoke fear about the consequences. Scenarios based on these assumptions were explored. If the system detected signs of dementia then this information could be distressing to the user. This raises questions about how the information should be communicated to the user, and the appropriate system response to different diagnostic signs. Using the OCC model, the source of anticipated emotions of fear and distress are the event (message), which has consequences for self (the user) with a specific impact when the feared expectation (diagnosis of dementia) is confirmed. Relief or fear confirmed are also possible depending on the results of follow-up tests. This may also have a general impact leading to distress and fear of the future. This is summarised in the template shown in Table 5.

The next step is to specify the system response. In this case the mirror emotion (relief) can be explored since the diagnosis is uncertain, so suggestions for follow-up tests can be specified to confirm or negate the initial diagnosis with reassuring messages that many initial signs turn out to be false alarms.

Table 5. Situation template: Cognitive impairment diagnosis. Situation: Diagnosis of problems, low confidence

\begin{tabular}{|c|c|}
\hline Agents \& actions & User, possibly their kin \\
\hline Objects & Text, graphs feedback presentation \\
\hline Events (previous) & $\begin{array}{l}\text { Message warning about possible cognitive impairment (patient } \\
\text { history) }\end{array}$ \\
\hline Expected emotions & Anxiety, fear, distress, relief \\
\hline System response & Mitigate consequences, reassure user, empathise \\
\hline Agent requirements & Agent sympathises with user, communicates \\
\hline Other requirements & $\begin{array}{l}\text { Supplementary information, communication with doctors, kin and } \\
\text { friends }\end{array}$ \\
\hline
\end{tabular}

Consulting medical experts with explanations of tests in memory clinics is another system response. The social emotion of empathy is another means of dealing with distress, hence requirements for social support might be explored, for instance the acceptability of letting close friends know via a social network. A range of scenarios 
(see Fig. 4) were developed to explore different means of communicating the potentially distressing message, with system responses ranging from no emotion (just the facts), to expression of empathy by agent characters. Other design options involved choice of media to deliver the message (text, voice, agent character plus voice/text), as well as the content and format of the message (polite, sympathetic tone).

Scenario: You are presented with evidence of memory problems from the computer monitor. How would you feel about the messages presented, and the followup advice to complete more self assessment tests?

Agent: " Sorry to disturb you, but I have found a few signs of problems with your memory. These might not be significant but I think it would be helpful to try a few follow-up tests: see the following link."

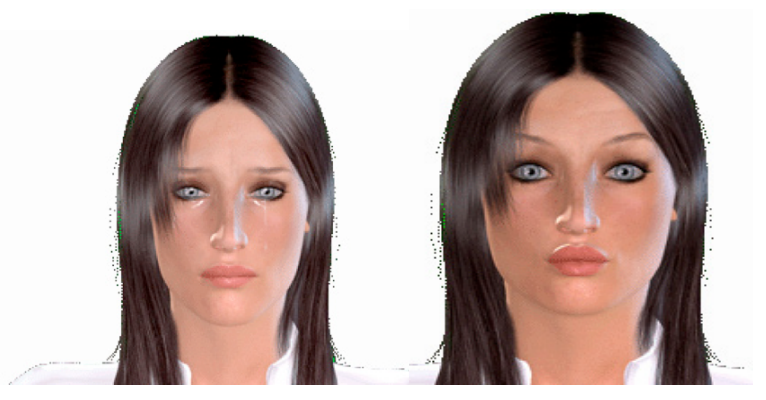

Fig. 4. Scenario and agent storyboard for the weak diagnostic signs situation

These scenarios of personal goals and motivations were investigated to identify possible barriers to system goals (to encourage self-referral for follow-up tests), for example self-denial that the user has a medical problem. Analysis of the storyboard scenarios showed individual differences in affective responses. Some users preferred simple factual communications, whereas others liked the empathetic agent. Older characters were suggested to match the user audience, also using a doctor to evoke more trust. Content options included simple explanations of the reasons for diagnosis, with limited disclosure of the information to close friends or kin in the user's social network. All users felt that, apart from letting their very best friend know if the follow-up tests did confirm the problem, any disclosure would cause them distress and unnecessary fear among friends.

Scenario analysis also produced insight into ethical concerns with use of e-mail content for text mining. Analysis scenarios presented fictitious e-mails with varying degrees of affective content which were then personalised for each individual or used more general language. Privacy/safety motivations and distress/fear emotional responses underpinned these scenarios since if access to e-mail content were not possible this could hinder the diagnostic ability of the system. Users were willing to allow access to e-mail content in general terms, but personalised emotive content raised anxieties and privacy fears. The problem of replies to e-mail becoming part of the content emerged during these scenarios as users pointed out that this potentially involved others and raised the question about how permission would be sought when it would be difficult to predict which friends or kin they would exchange messages 
with. The conclusion was to design filters so only user-authored content would be accessible.

\subsection{Evaluation}

The prototypes were evaluated in five workshops with a total of 24 participants (14 male, 10 female, age range 60-75, median 66), with a median four participants/session plus two facilitators. Prototype UIs presented feedback messages communicating potential early onset dementia to elicit users' reactions, feelings and ethical issues. Three prototype versions were presented in workshops and interviews: (i) the agent character interface produced using the method described in this paper, (ii) a minimal text message interface, using empathic text that closely matched the agent speech, and (iii) a minimal text interface with additional explanation justifying the feedback message. The additional information showed graphs based on fictitious recording of user behaviour, indicating where the threshold had been exceeded to trigger the feedback message. Time constraints imposed by the research project on the evaluation session precluded a conventional experimental design with use of usability/user experience questionnaires, so only limited quantitative data could be recorded. Problems raised in the workshops were explored further in 13 interviews following a similar approach. Questions in the interviews also probed users' reactions to fears/barriers for adopting the system and taking follow-up action after an alert message. Respondents ( 4 male, 9 female), ranging from 67 to 89 years old (median 72), were all interviewed in their own homes, apart from three sessions carried out in a community centre.

There was no consensus on choice of the design option (text/augmented text/agent), although a majority in all workshops favoured provision of more detail and the availability of regular reports (content). Use of the agent was favoured in all workshops as a backup to text, where participants suggested that self-help (how to cope) and explanation (dementia mitigation treatments) could be important motivators for persuading them to take follow-up action. Reaction to the agent design was mixed, with approximately $60 \%$ of the participants agreeing that the message spoken by the agent was more sympathetic that plain text, although several participants commented that the facial expression was difficult to interpret. In the interviews most respondents (8/13) favoured the plain text alert message over other design options, although a majority (11) agreed that the agent could be a useful supplement to the plain text, and $10 / 13$ preferred supplementary information to be presented by the agent rather than graphs. Consistent with the interviews, the value of the agent was seen to be in delivering additional information. The facial expression was interpreted by 10 participants as being empathetic and showing mild disappointment, although 3 could not discern any particular expression. Reaction to the agent designs was mixed. Overall, text was preferred, although the agent presentation was considered to be a useful supplement if it added value by providing more information. Design of the empathetic message may be more important that conveying emotion by facial expression. We did not test a non-empathetic version of the feedback message; however, all participants agreed that the tone of the message was appropriate. The choice of agent character (young female) was considered appropriate by most 
participants although several interviewees (7) preferred an older character, closer to their age group.

\subsection{Lessons Learned}

The design produced by the method was moderately successful. However the evaluation demonstrated that emotion design has to be set in a wider context of the role of characters in supplementing basic messages. The choice of the facial expression and empathetic message tone, which were informed by the method, were generally well received, although clearly there was room for improvement in agent's facial expression.

One problem with affect-oriented research is that people are rarely completely candid about expressing emotion [17]. Some users were concerned that they only felt emotion in real life and that imagining how they would feel in response to scenarios was not easy. Another problem was negative reaction to the agents; several users (6) preferred to communicate with real people rather than computer images in affective situations. However, motivations and discussion of feelings were productive when assessing responses to the agent designs. The analysis side of the method, eliciting emotional situations which might occur, appears to be more difficult than the synthesis-design side where reaction to specific agent designs is being assessed. Tools for developing prototype agents have proved successful in demonstrating a range of facial expressions and scripted interactions, so exploration of affective user-centred design does seem to be a promising approach. Although the method proposed separate analysis-response and planning pathways, in practice a combination of both was often necessary. For example, analysis of users' fears about access to sensitive e-mails needed to be combined with advice-giving (agent feedback) so that the system's diagnosis of potential problems could be explained by reference to the original content as well as other indicators. While the scenarios and the method were initially focused on UI design issues, in actual use the method stimulated more wide-ranging debate about affect in socio-technical system design. Users' response to different affective tones in feedback messages and means of presenting those messages, e.g. stronger advice and persuasion versus more neutral presentation of the system's analyses, sparked a debate about the overall conception of the system as either a persuasive agent that influenced users to refer themselves for medical attention or as a healthcare self-management system where the decision-making onus was left with the user.

\section{Discussion}

EUCD provides a systematic approach to exploring human motivations, emotions and attitudes for designing advanced UI technology where agent/character-based interfaces are becoming more common. Motivation and emotion analysis are particularly pertinent to social computing applications where computer-mediated interactions need to be considered. The EUCD method is not intended to supplant conventional HCI design approaches; instead, it augments scenario-based design [8] with person-oriented and social considerations. One further extension is to create a set 
of "affective claims" for situations so that the advantages and disadvantages of emotional responses and motivational frustrations can be considered. Even though the method is in its early stages of development, it does show some promise in producing insight into personal problems in applications where individual experience and goals are paramount. EUCD may also augment persuasive design methods such as the Fogg Behavior Model (FBM) [19] since it adds a scenario-based analysis approach and a richer taxonomy of emotions and motivation which can be applied to applications where the system's goal is to influence users [14, 39]. In a memory recall study of experience, Hassenzahl et al. [24] used Sheldon's taxonomy of needs, which are related to motivations, to demonstrate that users' needs and emotions positively influence both hedonic and pragmatic ratings of products. Hassenzahl's concept of hedonics [22] expresses users' attitudes to interactive products in terms of motivational goals and value judgements, which could provide a complementary perspective to the classifications in EUCD. While the emphasis of EUCD is on analysis and understanding of the implications of affective design on users, it could also be used for design guidance by directly applying the motivation and affect taxonomies. In this mode the method synthesises more general guidance on affective design [6] with scenario-based design exploration in the planning pathway.

While emotions and motivation are psychological constructs which require indepth knowledge for analysis of human problems, the EUCD method delivers a digestible sub-set of psychology, which could be used by non-experts. Experience to date has involved medical personnel who are conversant with the psychology of emotion from their training, so testing the method with non-experts is part of the future research agenda. To deliver the method's advice more effectively we will create a hypertext website so users can explore the links between motivation, emotions, obstacles and possible mitigations. Although the scenario and storyboard analysis has demonstrated that affective issues can be explored with users who are not experts, EUCD is not appropriate for creative use of emotions in entertainment and games applications where fear, anxiety and negative emotions might be manipulated for dramatic effect. Callele et al. [7] do address emotional design in games, although no heuristics linking types of emotional responses to design guidance are given. Desmet's emotional design methods and guidelines $[14,20]$ are closely related to EUCD, although they are based on a slightly different taxonomy of 25 emotions synthesised from several theories [13]. However, Desmet's design advice focuses on interactive products at the device level, similar to Hassenzahl's hedonics [23] (e.g. mobile phones), whereas EUCD has a narrower focus on applications and episodes within an interactive sequence.

Current sensory technology enables body posture and facial expression to be automatically analysed to detect emotional responses such as disappointment, enabling computer interfaces to portray appropriate emotional response [29]. Furthermore, the OCC model has been formalised [1] so there is the prospect of creating emotional analysis tools based on EUCD for agent-based specifications. In conclusion, EUCD extends HCI design methodology which has focused on human feelings and values $[11,21]$, as well as analysing the socio-technical implications of affective reactions to inappropriate features, tacit knowledge and managerial changes.

Ideally a validation study comparing design of an affective application with and without the EUCD method could have strengthened claims for the method's 
effectiveness. Unfortunately such method validation studies are expensive and very difficult to design since matching the context of application, users, and designers is hard to achieve. Although this study has several limitations, such as the preliminary evaluation of the method with a few users, it has produced interesting lessons and insight into how emotion might be employed in UI design in a wider context than persuasive technology. While the EUCD guidelines helped to stimulate design ideas, the method also had indirect effects such as initiating debate about the more general emotional impact of the system, as an empathetic friend or persuasive agent. The value of a detailed method such as EUCD may therefore be realised at different levels, although the trade-off between detailed advice and more general heuristic use of the method awaits further in-depth investigation of use in different applications.

\section{Acknowledgments}

The work described in this paper is funded by EPSRC project ref. EP/K015796/1 Software Architecture for Mental Health Self Management (SAMS).

\section{References}

[1] Adam, C., Herzig, A. and Longin, D. (2009) A logical formalization of the OCC theory of emotions. Synthese, 168, 201-248.

[2] Artificial Intelligence Foundation. ALICE chatterbots. Available online at www.alice.pandorabots.com [Accessed 2 February 2011]

[3] Bandura, A. (2001) Social cognitive theory of mass communication. Mahwah NJ: Lawrence Erlbaum Associates.

[4] Benford, S., Giannachi, G., Koleva, B. and Rodden, T. (2009) From interaction to trajectories: Designing coherent journeys through user experiences. Proceedings: $\mathrm{CHI}$ 2009, 27th International Conference on Human Factors in Computing Systems. pp. 709718. New York: ACM Press.

[5] Bickmore T. and Cassell, J. (2004). Social dialogue with embodied conversational agents. In J. van Kuppevelt, L. Dybkjaer and N.O. Bernsen (Eds) Natural, intelligent and effective interaction with multimodal dialogue systems. New York: Kluwer Academic.

[6] Brave, S. and Nass, C. (2003) Emotion in human-computer interaction. In J. Jacko and A. Sears (Eds) Handbook of human-computer interaction. Mahwah NJ: Lawrence Erlbaum Associates, Chapter 26.

[7] Callele, D., Neufeld, E. and Schneider, K. (2009) Augmenting emotional requirements with emotion markers and emotion prototypes. In Proceedings, RE 2009. pp. 373-374. Los Alamitos CA: IEEE Computer Society Press.

[8] Carroll, J.M. (2000) Making use: Scenario-based design of human-computer interactions. Cambridge, MA: MIT Press.

[9] Cassell, J. (2000) Embodied conversational interface agents. Communications of the $A C M, 43,70-80$.

[10] Chidambaram, V., Chiang, Y.-H. \& Mutlu, B. (2012) Designing persuasive robots: How robots might persuade people using vocal and nonverbal cues. In HRI '12: Proceedings of the 4th ACM/IEEE International Conference on Human Robot Interaction, pp 293-300. New York: ACM Press. 
[11] Cockton, G., Kujala, S. Nurkka, P. and Hölttä, T. (2009) Supporting worth mapping with sentence completion (Springer Lecture Notes in Computer Science, 5727). Berlin: Springer.

[12] Cooper, A., Reimann R. and Cronin, D. (2007) About Face 3: The essentials of interaction design. Indianapolis: Wiley.

[13] Desmet, P.M. (2012) Faces of product pleasure: 25 positive emotions in human-product interactions. International Journal of Design, 6(2).

[14] Desmet, P.M., Fokkinga, S.F., Ozkaramanli, D. and Yoon, J. (2016) Emotion-driven product design. Emotion Measurement, 405.

[15] Djajadiningrat, J.P., Gaver, W.W and Frens, J.W. (2000) Interaction relabelling and extreme characters: Methods for exploring aesthetic interactions. In Conference Proceedings, DIS-2000 Designing Interactive Systems: Processes, Practices Methods and Techniques. pp. 66-71. New York: ACM Press.

[16] Ekman, P. (1999) Basic emotions. In T. Dalgleish and M. Power (Eds), Handbook of cognition and emotion. Chichester: Wiley.

[17] Fineman, S. (2004) Understanding emotion at work. Thousand Oaks CA: Sage Publications.

[18] Fogg, B.J. (2003) Persuasive technology: Using computers to change what we think and do. San Francisco: Morgan Kaufmann.

[19] Fogg, B.J. (2009) A behaviour model for persausive design. In Proceedings Persuasive 2009: 4th International Conference on Persuasive Technology. New York: ACM Press.

[20] Fokkinga, S.F. and Desmet, P.M. (2013) Ten ways to design for disgust, sadness, and other enjoyments: A design approach to enrich product experiences with negative emotions. International Journal of Design, 7(1).

[21] Friedman, B. (2008) Value sensitive design. In D. Schular (Ed.) Liberating voices: A pattern language for communication revolution. pp. 366-368. Cambridge MA: MIT Press.

[22] Hassenzahl, M. (2004) The interplay of beauty, goodness, and usability in interactive products. Human-Computer-Interaction, 19(4), 319-349.

[23] Hassenzahl, M. and Monk, A. (2010). The inference of perceived usability from beauty. Human-Computer Interaction, 25(3), 235-260.

[24] Hassenzahl, M., Diefenbach, S. and Göritz, A.S. (2010) Needs, affect, and interactive products: Facets of user experience. Interacting with Computers, 22(5), 353-362.

[25] Hassenzahl, M., Schöbel, M. and Trautmann, T. (2008) How motivational orientation influences the evaluation and choice of hedonic and pragmatic interactive products: the role of regulatory focus. Interacting with Computers, 20, 473-479.

[26] Johnson, D., \& Wiles, J. (2003). Effective affective user interface design in games. Ergonomics, 46, 1332-1345.

[27] Klein J., Moon, Y. and Picard, R.W. (2002) This computer responds to user frustration: Theory, design and results. Interacting with Computers, 14, 199-140.

[28] Maslow, A.H., Frager, R., McReynolds, C., Cox R. and Fadiman, J. (1987) Motivation and personality. New York: Addison Wesley-Longman.

[29] McDuff, D., Karlson, A., Kapoor, A., Roseway, A. and Czerwinski, M. (2012). AffectAura: An intelligent system for emotional memory. In Proceedings CHI-2012. pp 848-858. New York: ACM Press.

[30] Norman, D.A. (1999) The design of everyday things. New York: Basic Books.

[31] Norman, D.A. (2004) Emotional design: Why we love (or hate) everyday things. New York: Basic Books.

[32] Ortony, A., Clore, G.L. and Collins, A. (1988). The cognitive structure of emotions. Cambridge: Cambridge University Press.

[33] Partalaa, T. and Veikko, S. (2004) The effects of affective interventions in humancomputer interaction. Interacting with Computers, 16, 295-309. 
[34] Pelachaud, C., Carofiglio, V., De Carolis, B. and De Rosis, F. (2002) Embodied virtual agent in information delivering application. In Proceedings, First International Joint Conference on Autonomous Agents and Multi-Agent Systems. New York: ACM Press.

[35] Picard, R.W. (1997) Affective computing. Cambridge MA: MIT Press.

[36] Picard, R.W. (2003) Affective computing: challenges. International Journal of HumanComputer Studies, 59, 55-64.

[37] Preece, J. and Maloney-Krichmar, D. (2003) Online communities. In J. Jacko and A. Sears (Eds) Handbook of human-computer interaction. Mahwah NJ: Lawrence Erlbaum Associates, pp. 596-620.

[38] Reeves, B and Nass, C. (1996) The media equation: How people treat computers, television and new media like real people and places. Stanford CA/Cambridge: CLSI/Cambridge University Press.

[39] Torning, K. and Olinas-Kukkonen, H. (2009) Persuasive design methods: State of the art review. In Proceedings Persuasive 200: 4th International Conference on Persuasive Technology. New York: ACM Press. 